\title{
Expression Measurement Object
}

National Cancer Institute

\section{Source}

National Cancer Institute. Expression Measurement Object. NCI Thesaurus. Code C41093.

An object representing a structure that is capable of measuring the absolute or relative amount of a given compound. 